\title{
Investigating PAH relative reactivity using congener profiles, quinone measurements and back trajectories
}

\author{
M. S. Alam ${ }^{1}$, J. M. Delgado-Saborit ${ }^{1}$, C. Stark ${ }^{1}$, and R. M. Harrison ${ }^{1,2}$ \\ ${ }^{1}$ Division of Environmental Health \& Risk Management, School of Geography, Earth \& Environmental Sciences, University \\ of Birmingham, Edgbaston, Birmingham, B15 2TT, UK \\ ${ }^{2}$ Department of Environmental Sciences/Center of Excellence in Environmental Studies, King Abdulaziz University, \\ Jeddah, 21589, Saudi Arabia
}

Correspondence to: R. M. Harrison (r.m.harrison@bham.ac.uk)

Received: 22 July 2013 - Published in Atmos. Chem. Phys. Discuss.: 8 October 2013

Revised: 15 January 2014 - Accepted: 29 January 2014 - Published: 10 March 2014

\begin{abstract}
Vapour and particle-associated concentrations of 15 polycyclic aromatic hydrocarbons (PAH) and $11 \mathrm{PAH}$ quinones have been measured in winter and summer campaigns at the rural site, Weybourne in eastern England. Concentrations of individual PAH are relatively smaller than average concentrations measured previously at urban sites in the UK. The concentrations of PAH of the air masses originating from southern England and mainland UK are significantly larger than those from Eastern Europe and the North Atlantic, while quinone to parent $\mathrm{PAH}$ ratios show an inverse behaviour, being highest in the more aged North Atlantic polar air masses. While concentrations of 1,2-naphthoquinone decline from winter to summer, those of 1,4-naphthoquinone and anthraquinone increase suggesting a photochemical formation pathway. A comparison of congener concentration profiles measured at Weybourne with those from an urban source area (Birmingham) reveals differential losses at the rural site, especially evident in fluoranthene: pyrene ratios and consistent with the known rates of vapour phase reactions of 3 and 4 ring compounds with hydroxyl radical. The ratios of quinones to their parent PAH at Weybourne are greater than those in the urban source area indicating either more rapid loss processes for $\mathrm{PAH}$, or formation of quinones during advection of the air mass, or probably both.
\end{abstract}

\section{Introduction}

Polycyclic aromatic hydrocarbons (PAHs) are ubiquitous organic pollutants, present in the atmosphere both in the vapour phase and associated with particulate matter (PM). PAHs are often measured in studies of atmospheric chemistry or health effects of air pollution, owing to their known carcinogenic effects (Yu, 2002). Recently, PAH quinone derivatives have also become a focus of interest, primarily because they can contribute to oxidative stress, and are believed by some to be more toxic than their parent PAH compounds (Sidhu et al., 2005; Walgraeve et al., 2010). Rarely however, are such compounds measured in the same airborne samples, despite the need to do so to elucidate atmospheric processing of PAH.

Oxygenated PAH, including quinones are released into the atmosphere along with PAH during incomplete combustion processes (Iinuma et al., 2007; Layshock et al., 2010; Valavanidis et al., 2006). Vapour phase and heterogeneous atmospheric processing of PAHs can yield further quinone products via reactions with atmospheric oxidants including $\mathrm{OH}$, $\mathrm{NO}_{3}$ and $\mathrm{O}_{3}$ (Atkinson and Arey, 2007). However, the relative contribution to the observed atmospheric burden of PAH quinone derivatives from direct combustion emissions and secondary atmospheric reactions is far from fully understood (Keyte et al., 2013).

Although there are many reports of oxygenated-PAHs measured in airborne analyses (Walgraeve et al., 2010), which include ketones, carboxaldehydes and diones, limited measurements of quinones alongside PAH have been reported. Wang et al. (2011) reported the measurements of 
three quinones, nitro-PAH (NPAH) and associated parent PAH compounds, in a toxicity study of $\mathrm{PM}_{2.5}$ during the Beijing Olympic Games. They found that although most of the parent PAH, NPAH and oxygenated-PAH (OPAH) concentrations correlated with $\mathrm{NO}$ and $\mathrm{NO}_{2}$, only the parent PAHs were correlated with $\mathrm{CO}$ and $\mathrm{SO}_{2}$ concentrations. The authors suggested that the OPAHs were therefore primarily associated with local emissions and local photochemical formation. Albinet and co-workers reported the measurement of 15 PAH compounds using HPLC with fluorescence/UV detection, while determining 17 NPAH and 9 OPAH (2 of which were quinone) compounds simultaneously using GCMS with negative ion chemical ionisation (NICI) (Albinet et al., 2006, 2007a, b, 2008a, b). More recently, Wingfors et al. (2011) measured 18 OPAHs, 6 of which were quinones, in an urban environment, but were only able to measure 3 of the associated parent PAH compounds. The most common of the measured airborne quinone compounds reported in the literature to date are 9,10-anthraquinone and 9,10-phenanthraquinone; however, many studies have also reported quinone compounds including 1,2-naphthoquinone and 1,4-naphthoquinone from diesel and gasoline vehicle emissions (Cho et al., 2004; Jakober et al., 2007).

Recently, in a study from this laboratory, we reported a methodology to measure quinones and PAHs in the gaseous and particulate phases in ambient air, utilising GC-MS (Delgado-Saborit et al., 2013a). This included the first measurements for a range of quinones with a comparison of vapour and particulate phases, at an urban site in Birmingham with concentrations being of the same order of magnitude as their parent PAHs. In the present study we utilise the previously reported methodology to determine the airborne concentrations of 15 PAHs and 11 quinones, at a rural site on the North Sea coast, Weybourne, UK. Quinone to parentPAH ratios combined with back trajectories are used to assess the long range chemical transport and relative contribution of potential sources for measurements made at the site.

\section{Experimental}

\subsection{Site location}

Sampling was conducted at the Weybourne Atmospheric Observatory $\left(52^{\circ} 57^{\prime} \mathrm{N} 1^{\circ} 07^{\prime} \mathrm{E}\right)$ located on the North Norfolk coast. The observatory is located in a field approximately $100 \mathrm{~m}$ from the sea and $1 \mathrm{~km}$ away (northwest) from the nearest village. The area is surrounded by agricultural land with the closest city, Norwich, approximately $50 \mathrm{~km}$ SSE. The location receives a variety of Atlantic, Arctic, European, UK and North Sea air masses, owing to the rapidly changing wind directions. A comprehensive description of the site is given elsewhere (Penkett et al., 1999).

\subsection{Particle and vapour phase sampling}

Daily particulate $\left(\mathrm{PM}_{2.5}\right.$ and $\left.\mathrm{PM}_{2.5-10}\right)$ and vapour phase (PUFs) samples were collected over two one month periods, during winter (2 February 2010-2 March 2010) and summer (6 August 2010-2 September 2010), using a high volume air sampler TE-6070 (Tisch Environmental, Inc.). The high volume sampler typically draws large volumes of air in the range of $1600-2000 \mathrm{~m}^{3}$ over a $24 \mathrm{~h}$ period, through a $20 \mathrm{~cm} \times 25 \mathrm{~cm}$ quartz fibre filter (QMA) substrate. A parallel plate denuder coated with XAD-4 (20/60 mesh, SigmaAldrich, England) was also used to collect vapour phase compounds during winter and summer campaigns with a sampling flow rate range of 10-20 LPM. Vapour phase concentrations measured using PUF substrates and parallel plate denuders for the winter campaign were in good agreement of $\pm 10 \%$. Procedures prior to sampling have been discussed in detail in Delgado-Saborit et al. (2013a). Briefly, filters were preheated at $400^{\circ} \mathrm{C}$ for $48 \mathrm{~h}$ in a box furnace, wrapped in clean preheated foil, placed in a cardboard box, and sealed in an airtight metallic box. The polyurethane foam (PUF) were pre-cleaned prior to their use in the field in a Soxhlet using dichloromethane for $24 \mathrm{~h}$, where no degradation effect was observed. The solvent was later drained and the PUFs were left to dry in a sealed metal container under a stream of nitrogen. The cleaned and dried PUFs were sealed in airtight plastic bags and stored in a freezer. The metal denuder collection plates were placed into an airtight sealed denuder and shaken whilst in contact with XAD-4 suspended in dichloromethane to ensure an even coating of the plates (see Delgado-Saborit et al., 2013b). The plates were subsequently dried under a nitrogen flow, removed from the denuder holder, wrapped in aluminium foil and placed inside an airtight bag in a freezer. After exposure, the filters, PUFs and denuder plates were wrapped separately with clean pre-heated foil, enclosed in airtight plastic bags and stored under conditions of approximately $-18^{\circ} \mathrm{C}$ until analysis.

\subsection{Sample analyses}

Samples were analysed for 15 PAHs and 11 quinones using the methodology described previously (Delgado-Saborit et al., 2013a). Briefly, filters, PUFs and denuders were spiked with $1000 \mathrm{pg} \mu \mathrm{L}^{-1}$ deuterated internal standards for quantification (a list of these compounds is available in the Supplementary Material). Filters were immersed in DCM and ultrasonicated at $20^{\circ} \mathrm{C}$ for $15 \mathrm{~min}$. The extract was subsequently dried and cleaned with a chromatography column filled with $0.5 \mathrm{~g}$ of anhydrous sodium sulphate (puriss grade for HPLC). The cleaned extract was split into two equal parts, where one half was further concentrated to $50 \mu \mathrm{L}$ under a gentle nitrogen flow and the other derivatised as outlined below. PUFs were immersed in $100 \mathrm{~mL}$ of DCM and ultrasonicated at $20^{\circ} \mathrm{C}$ for $20 \mathrm{~min}$. Airtight closed denuders filled with $200 \mathrm{~mL}$ of DCM were shaken for $10 \mathrm{~min}$ changing orientation every 
two minutes. In both cases, the extract was concentrated to $10 \mathrm{~mL}$ using nitrogen, and subsequently dried and cleaned as described for the filters above.

The second part of the extract was derivatised in order to convert five quinones to their diacetyl derivatives (Cho et al., 2004; Chung et al., 2006; Delgado-Saborit et al., 2013a). Briefly, the extract was concentrated under a gentle nitrogen flow, followed by the addition of acetic anhydride $(200 \mu \mathrm{L})$ and zinc $(100 \mathrm{mg})$. The mixture was heated at $80^{\circ} \mathrm{C}$ with a heating block for $15 \mathrm{~min}$, mixing on a vortex every $5 \mathrm{~min}$. This procedure was repeated and then allowed to cool to room temperature, followed by the addition of pentane $(3 \mathrm{~mL})$ and $0.5 \mathrm{~mL}$ of water. The pentane layer was removed and the sample was further concentrated under nitrogen to $100 \mu \mathrm{L}$. This concentrated sample volume was transferred to a $250 \mu \mathrm{L} \mathrm{GC}$ insert, further evaporated under nitrogen to dryness and reconstituted in $25 \mu \mathrm{L}$ of recovery standard (i.e. pterphenyl- $\left.\mathrm{d}_{14}\right)$. Derivatised samples were stored in the GC inserter vials in a freezer at $-20^{\circ} \mathrm{C}$ until analysis.

The samples were analysed using an Agilent Technologies 6890 Gas Chromatograph (GC) equipped with an Agilent HP-5MS, non-polar capillary column $(30 \mathrm{~m}, 0.25 \mathrm{~mm}$ ID, $0.25 \mu \mathrm{m}$ film thickness $-5 \%$ phenylpolysiloxane), in tandem with a $5973 \mathrm{~N}$ Mass Spectrometer (MS) for the PAH and quinone analysis. Quality assurance and further information on the experimental procedure can be found in DelgadoSaborit et al. (2013a).

\subsection{Back trajectories}

The National Oceanographic and Atmospheric Administration's (NOAA) Hybrid Single Particle Langrangian Integrated Trajectory model (HYSPLIT4) was utilised to evaluate the source regions of air masses encountered at the sampling location. Back trajectories were simulated using Global Data Assimilation System (GDAS) meteorological data, containing 3 hourly, $1^{\circ}$, pressure level data for analysis and forecasting. $72 \mathrm{~h}$ back trajectories were simulated every hour from 00:00 GMT, 1 February 2010 to 23:00, 3 March 2010 for the winter campaign and from 00:00 5 August 2010 to 23:00, 4 September 2010 for the summer campaign resulting in 744 and 720 back trajectories respectively, at 10, 100 and $500 \mathrm{~m}$ air mass heights.

The average air temperatures measured during the winter and summer campaigns were $2.9 \pm 1.8$ and $16.0 \pm 2.7^{\circ} \mathrm{C}$, respectively; where the indicated uncertainty is the standard deviation of hourly measured data.

\section{Results and discussion}

\subsection{PAH concentrations}

Concentrations of individual PAH are 20-140 times smaller than average concentrations at an English urban site. The average concentrations of vapour and particulate phase PAH compounds measured during the winter and summer campaigns are shown in Table 1. Concentrations did not vary greatly between seasons, albeit statistically significant ( $t$ test, $p<0.05$ ), with average total concentrations for all measured PAH during winter exceeding those during summer. Concentrations of PAHs measured in this study are lower than urban environment measurements from the UK (Alam et al., 2013; Harrison et al., 1996), as would be expected for the site location and in reasonable agreement with background concentrations measured in southeastern Finland (Vestenius et al., 2011).

In general, high molecular weight (HMW) PAH compounds were present in relatively lower concentrations than compounds of lower molecular weight (LMW). LMW $(<228 \mathrm{Da}) \mathrm{PAHs}$ were predominantly in the vapour phase, where phenanthrene was found to be the most abundant PAH measured at an average total (vapour + particulate) concentration of 1.10 and $0.81 \mathrm{ng} \mathrm{m}^{-3}$ in the winter and summer, respectively. Interestingly, a larger percentage of the concentration of some PAHs were partitioned in the vapour phase during the winter than in the summer, see Table 1. For example, 51 and $33 \%$ of the total average concentration of benzo(a)anthracene was present in the vapour phase during the winter and summer, respectively. This may reflect faster gas phase reaction rates with atmospheric oxidants $\left(\mathrm{OH}, \mathrm{O}_{3}\right.$ and $\mathrm{NO}_{3}$ ) in the summer where oxidant levels are higher. Equilibration between the phases seems likely to be relatively slow.

The average total concentration of PAH in the summer campaign was approximately $70 \%$ of the winter campaign sum. There is scatter around this value for individual compounds, the most marked difference being for retene. The very high winter / summer ratio for retene is likely to reflect its emission during wood burning (Bari et al., 2009). The seasonal difference for the other compounds is seen in the high MW as well as the low MW compounds and is not explicable purely by greater partitioning to vapour in the warmer summer campaign, although this will be a factor. Other reasons include greater emissions in the winter due to increased fossil fuel usage, the usual seasonal increase in primary pollutants in winter due to poorer dispersion conditions, and a different frequency of air mass types, as this strongly influences concentrations during an episode (see below).

\subsection{Quinone concentrations}

The average concentrations of vapour and particulate phase quinone compounds measured during summer and winter are shown in Table 1. We report the first remote site observations for 2-methylanthraquinone (2MAQ), 2,3dimethylanthraquinone (2,3DMAQ), benzo(a)pyrene-6,12dione $(\mathrm{B}(\mathrm{a}) \mathrm{P}-6,12)$ and benzo(a)pyrene-1,6-dione $(\mathrm{B}(\mathrm{a}) \mathrm{P}$ $1,6)$ using GC-MS. Quinones with molecular mass $<208 \mathrm{Da}$ were mainly found in the vapour phase, consistent with previous studies, who reported that $>50 \%$ LMW OPAH 
Table 1. Vapour and particulate phase concentrations of PAH and quinone compounds during summer and winter seasons.

\begin{tabular}{|c|c|c|c|c|c|c|c|c|c|c|c|c|c|}
\hline \multirow[t]{2}{*}{ Compound } & \multirow[t]{2}{*}{ MW } & \multicolumn{5}{|c|}{ Winter concentration $\left(\mathrm{pg} \mathrm{m}^{-3}\right)$} & \multirow{2}{*}{$\begin{array}{r}\% \text { Vapour } \\
\text { phase }\end{array}$} & \multicolumn{5}{|c|}{ Summer concentration $\left(\mathrm{pg} \mathrm{m}^{-3}\right)$} & \multirow{2}{*}{$\begin{array}{r}\% \text { Vapour } \\
\text { phase }\end{array}$} \\
\hline & & Vapour (v) & Fine $\mathrm{PM}_{2.5}$ & Coarse $\mathrm{PM}_{2.5-10}$ & $\Sigma$ particle $(p)$ & Total $(v+p)$ & & Vapour $(v)$ & Fine $\mathrm{PM}_{2.5}$ & Coarse $\mathrm{PM}_{2.5-10}$ & $\Sigma$ particle $(p)$ & Total $(v+p)$ & \\
\hline PHE & 178 & 820.0 & 189.0 & 94.0 & 283.0 & 1103.0 & 74 & 636.0 & 120.0 & 58.0 & 178.0 & 814.0 & 78 \\
\hline ANT & 178 & 89.0 & 56.0 & 15.0 & 71.0 & 160.0 & 56 & 68.0 & 55.0 & 7.0 & 62.0 & 130.0 & 52 \\
\hline FLU & 202 & 226.0 & 96.0 & 23.0 & 119.0 & 345.0 & 66 & 182.0 & 73.0 & 15.0 & 88.0 & 270.0 & 67 \\
\hline PYR & 202 & 102.0 & 50.0 & 15.0 & 65.0 & 167.0 & 61 & 80.0 & 35.0 & 11.0 & 46.0 & 126.0 & 63 \\
\hline $\mathrm{B}(\mathrm{a}) \mathrm{A}$ & 228 & 44.0 & 31.0 & 11.0 & 42.0 & 86.0 & 51 & 15.0 & 23.5 & 7.0 & 30.5 & 46.0 & 33 \\
\hline CHR & 228 & 19.0 & 38.0 & 12.0 & 50.0 & 69.0 & 28 & 12.5 & 25.0 & 8.0 & 33.0 & 45.5 & 27 \\
\hline RET & 234 & 25.0 & 21.0 & 8.0 & 29.0 & 54.0 & 46 & 5.5 & 8.0 & 4.0 & 12.0 & 17.5 & 31 \\
\hline $\mathrm{B}(\mathrm{b}) \mathrm{F}$ & 252 & 130.0 & 53.0 & 15.0 & 68.0 & 198.0 & 66 & 58.0 & 38.0 & 15.0 & 53.0 & 111.0 & 52 \\
\hline $\mathrm{B}(\mathrm{k}) \mathrm{F}$ & 252 & 59.0 & 21.0 & 8.0 & 29.0 & 88.0 & 67 & 24.0 & 17.0 & 8.0 & 25.0 & 49.0 & 49 \\
\hline $\mathrm{B}(\mathrm{e}) \mathrm{P}$ & 252 & 3.5 & 21.0 & 9.0 & 30.0 & 33.5 & 10 & BDL & 17.0 & 4.5 & 21.5 & 21.5 & ND \\
\hline $\mathrm{B}(\mathrm{a}) \mathrm{P}$ & 252 & 3.0 & 16.0 & 8.0 & 24.0 & 27.0 & 11 & BDL & 14.0 & 7.0 & 21.0 & 21.0 & ND \\
\hline IND & 276 & 2.5 & 14.0 & 4.5 & 18.5 & 21.0 & 12 & BDL & 7.0 & 4.0 & 11.0 & 11.0 & ND \\
\hline $\mathrm{D}(\mathrm{ah}) \mathrm{A}$ & 276 & 2.5 & 10.0 & 6.0 & 16.0 & 18.5 & 14 & BDL & 3.5 & 3.0 & 6.5 & 6.5 & ND \\
\hline B(ghi)P & 278 & 1.0 & 9.5 & 5.0 & 14.5 & 15.5 & 6 & BDL & 4.0 & 3.0 & 7.0 & 7.0 & ND \\
\hline $\mathrm{COR}$ & 300 & 0.5 & 3.0 & 2.5 & 5.5 & 6.0 & 8 & BDL & 1.5 & 1.0 & 2.5 & 2.5 & ND \\
\hline $1,2 \mathrm{NQ}$ & 158 & 458.0 & 24.0 & 12.0 & 36.0 & 494.0 & 93 & 356.0 & 12.0 & 8.0 & 20.0 & 376.0 & 95 \\
\hline $1,4 \mathrm{NQ}$ & 158 & 327.0 & 12.0 & 4.0 & 16.0 & 343.0 & 95 & 579.0 & 23.0 & 10.0 & 33.0 & 612.0 & 95 \\
\hline $2 \mathrm{MNQ}$ & 172 & 300.0 & 12.0 & 3.0 & 15.0 & 315.0 & 95 & 200.0 & 8.0 & 3.0 & 11.0 & 211.0 & 95 \\
\hline PQ & 208 & 72.0 & 58.0 & 22.0 & 80.0 & 152.0 & 47 & 53.0 & 43.0 & 13.0 & 56.0 & 109.0 & 49 \\
\hline $\mathrm{AQ}$ & 208 & 9.0 & 37.0 & 18.0 & 55.0 & 64.0 & 14 & 38.0 & 33.0 & 11.0 & 44.0 & 82.0 & 46 \\
\hline 2MAQ & 222 & 60.0 & 35.0 & 16.0 & 51.0 & 111.0 & 54 & 50.0 & 29.0 & 13.0 & 42.0 & 92.0 & 54 \\
\hline 23DMAQ & 236 & 34.0 & 29.0 & 11.0 & 40.0 & 74.0 & 46 & 23.0 & 20.0 & 9.0 & 29.0 & 52.0 & 45 \\
\hline B(a)A-7,12 & 258 & 11.0 & 15.0 & 6.0 & 21.0 & 32.0 & 34 & 18.0 & 11.0 & 3.0 & 14.0 & 32.0 & 56 \\
\hline $5,12 \mathrm{NAQ}$ & 258 & 12.0 & 16.0 & 6.0 & 22.0 & 34.0 & 35 & 9.0 & 11.0 & 4.0 & 15.0 & 24.0 & 38 \\
\hline B(a)P-6,12 & 282 & BDL & 4.5 & BDL & 4.5 & 4.5 & ND & BDL & BDL & BDL & BDL & BDL & ND \\
\hline B(a)P-1,6 & 282 & BDL & 4.0 & BDL & 4.0 & 4.0 & ND & BDL & BDL & BDL & BDL & BDL & ND \\
\hline
\end{tabular}

compounds ( $\mathrm{MW}<202 \mathrm{Da}$ ) were present in the gas phase (Albinet et al., 2008a). Approximately $95 \%$ of 1,2naphthoquinone $(1,2 \mathrm{NQ})$ 1,4-naphthoquinone $(1,4 \mathrm{NQ})$ and 2-methyl-1,4-naphthoquinone (2MNQ) were measured in the vapour phase, irrespective of seasons. A smaller percentage of vapour phase, approximately 50 and $20 \%$, was measured for phenanthraquinone (PQ) and anthraquinone (AQ) during the winter, respectively; but vapour phase AQ during the summer was approximately $50 \%$. This is in agreement with previous measurements and the larger percentage of particulate phase measured for these quinones in comparison to PAHs of similar MW may indicate that the greater polarity of these quinones may lead to an increased tendency to partition into the particulate phase (DelgadoSaborit et al., 2013a). The average vapour phase concentrations for all measured quinones during the winter exceeded those during the summer, with the exception of 1,4NQ, AQ and benzo(a)anthracene-7,12-dione (B(a)A-7,12). Interestingly, this coincides with the percentage decrease of vapour phase ANT and B(a)A observed during the summer (see Table 1), suggesting that an increase in gas phase reactions of ANT and $\mathrm{B}(\mathrm{a}) \mathrm{A}$ with atmospheric oxidants during the summer may give rise to these elevated levels of vapour phase $\mathrm{AQ}$ and $\mathrm{B}(\mathrm{a}) \mathrm{A}-7,12$.

Relatively greater partitioning of all quinones into the particulate phase was found for compounds with MW > 222 Da, during the winter, see Table 1 . Previous measurements at trafficked and urban background sites in Birmingham indicated that $5 \%$ of 5,12 -naphthacenequinone $(5,12 \mathrm{NAQ})$ was found in the vapour phase (Alam et al., 2013), whereas approximately 35 and $18 \%$ of $5,12 \mathrm{NAQ}$ was measured in the vapour phase, during the winter and summer respectively, in this study, thus reflecting the volatility of this compound. The average particulate phase quinone concentrations measured during the winter were greater than those measured during the summer, again with the exception of $1,4 \mathrm{NQ}$. A paired $t$ test revealed these seasonal differences (vapour and particulate phase) to be statistically significant $(p<0.05)$ for all quinones except for vapour phase $2 \mathrm{MAQ}$, which has been suggested to be heavily traffic related (Alam et al., 2013).

Like PAHs, quinones are emitted to the atmosphere through incomplete combustion processes and biomass burning, but are also formed from atmospheric reactions of their parent PAH compounds. Thus, quinones, as with PAHs should demonstrate seasonal variability, which has been demonstrated by numerous studies (Eiguren-Fernandez et al., 2008, 2004; Miguel et al., 2004). The average total concentration of quinone compounds in the summer campaign was approximately $95 \%$ of the winter campaign sum. Again there is significant scatter around this value for individual compounds, particularly 1,4NQ, AQ and B(a)A-7,12. Quinone/PAH ratios were consistently higher in summer than winter, as exemplified by the data in Table S2.

Chemical reactions are likely to be greater in summer due to higher reactant concentrations (especially hydroxyl radical) but most quinones also show a winter / summer ratio broadly similar to the PAH suggesting that they have largely primary origins. There are however some notable exceptions. Vapour phase concentrations of 1,4NQ, AQ and B(a)A-7,12 were a factor of 1.8, 4.2 and 1.6 times greater in the summer than in the winter, respectively. The average total concentrations for 1,4NQ and AQ were a factor of 1.8 and 1.3 times greater in the summer, respectively. This may indicate that photochemical activity is a major contributor to formation of 
$\mathrm{AQ}, 1,4 \mathrm{NQ}$ and potentially of $\mathrm{B}(\mathrm{a}) \mathrm{A}-7,12$ during the summer.

Furthermore, the total concentration of $1,2 \mathrm{NQ}$ was $24 \%$ lower during the summer, whereas the concentration of $1,4 \mathrm{NQ}$ was approximately $78 \%$ larger. This may indicate that photochemical activity is a major contributor to $1,4 \mathrm{NQ}$ formation during the summer, consistent with the levels reported for downwind sites such as Lake Arrowhead and Lancaster in Southern California (Eiguren-Fernandez et al., 2008). The Weybourne Observatory Site is remotely located but frequently downwind of the London conurbation (Cardenas et al., 1998). Higher concentrations of 1,4NQ during the summer, therefore, may suggest a more important contribution of photochemistry, resulting from transformation processes occurring during regional transport.

\subsection{Back trajectories}

$72 \mathrm{~h}$ back trajectories were calculated with $1 \mathrm{~h}$ intervals for the winter and summer sampling campaigns, totalling 744 and 720 back trajectories, respectively. Owing to the rapidly changing wind directions and the variety of air masses arriving from the Atlantic, Arctic, European, UK and North Sea areas, a cluster analysis for the back trajectories was completed to group similar trajectories together, using HYPLIT4. A 6 and 3 cluster mean was identified by the simulations for winter and summer campaigns, respectively, as illustrated in Fig. S1a and b, respectively. Although this gives an indication of where the air masses arrive from at the Weybourne Observatory site, it does not show the day to day changes in air mass direction. Thus back trajectories were identified for each day of the 30 day sampling period and related to the $\mathrm{PAH}$ and quinone concentrations, for greater accuracy. The variation of the air mass trajectories for the $24 \mathrm{~h}$ sampling period is shown in Table S1. The 6 clusters identified during the winter were further grouped together to form 3 clusters according to geographical origin, i.e. air masses originating from the North sea and Scandinavia were combined (red), Eastern and Southern Europe were combined (green) and London and mainland UK were combined (blue) (see Fig. S1a). A minimum of 15 out of 24 hourly trajectories within a day could be assigned to one cluster (or 2 combined clusters, in winter) during the winter $(6,16$ and 21 February 2010) and summer (23 August 2010). The hourly trajectories for 8 and 15 days during the winter and summer sampling periods, respectively, were stable and all assigned to one cluster (or 2 combined clusters, in winter), see Table S1.

Figure 1 illustrates that the total PAH concentration (i.e. sum of particulate and vapour phases) undergoes very similar temporal evolution to $\mathrm{SO}_{2}$ throughout the winter sampling period $\left(r^{2}=0.65\right)$. The three different colours within Fig. 1 signify the three different periods where air masses were traced back to the North Sea and Scandinavia, London and mainland UK and Eastern and Southern Europe, and correspond to the three colours illustrated in Fig. S1a. The

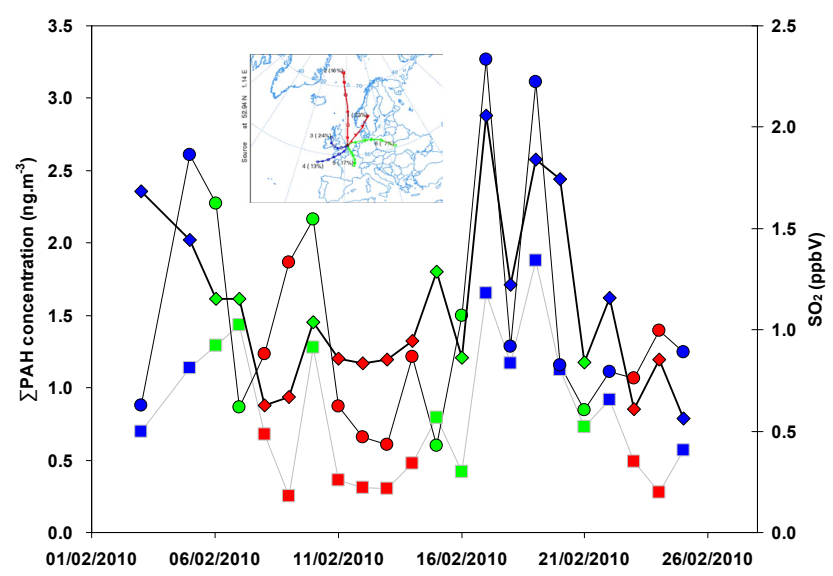

Fig. 1. Temporal trend of $\mathrm{SO}_{2}$ (secondary axis, diamonds), $\sum \mathrm{PAH}$ particulate phase (squares) and vapour phase (circles) for the winter sampling period 2 February 2010 to 25 February 2010. Colours signify three grouped air masses determined by cluster analysis, see embedded image and/or Fig. S1a for colour codes.

lower $\mathrm{PAH}$ (and $\mathrm{SO}_{2}$ ) concentrations during the sampling period 11 February 2010 to 14 February 2010 are due to the air masses coming from the remote areas of the North Sea and Scandinavia; whereas intermediate concentrations of $\mathrm{PAH}$ (and $\mathrm{SO}_{2}$ ) are observed when the air mass arrives from Eastern and Southern Europe and the highest relate to air masses arriving after passage over southeast England and mainland UK. This suggests that source regions dominate the winter campaign PAH concentrations (17 February 2010 to 20 February 2010), see Fig. 1. The concentrations of PAH of the air masses originating from southern England and mainland UK are statistically larger than those from Eastern Europe and the North Atlantic ( $t$ test, $p<0.10)$.

Similarly, during the summer, lower PAH concentrations were measured during sampling periods 13 August 2010 to 16 August 2010 and 30 August 2010 to 02 September 2010, when air masses originated from the North Sea, see Fig. S1b.

\subsection{Ratios of quinone to parent-PAH compounds}

The ratio of the concentration of an oxidation product quinone to that of its parent PAH together with information extracted from back trajectories can be used as an indicator of the contribution of atmospheric reactions to the concentration of quinones in the atmosphere. For example, McKinney et al. (1999) reported the ratios of AQ to anthracene (ANT) for several coastal marine sediments (McKinney et al., 1999). The differing ratios were attributed to atmospheric deposition at remote sites (ratio $>1$ ) and direct discharge to highly contaminated industrial harbours (ratio $<1$ ). Although these quinone to parent-PAH ratios can be indicative of the rate of transformation of PAH into quinones, they are not definitive since quinones can also be emitted directly from combustion processes as described previously (Layshock et 
al., 2010; Walgraeve et al., 2010). The rates of reaction of the quinones also need to be considered, but are largely unknown. Quinone to parent PAH ratios can also be influenced by sampling location and temperature, as this may influence the gas to particle partitioning of PAHs and OPAHs (Alam et al., 2013). A number of OPAH / PAH ratios were studied by Walgraeve et al. (2010) during the summer and winter, finding a large range of ratios which were explained by the importance of photochemical activity during the summer. Wingfors et al. (2011) calculated ratios for AQ and B(a)A7,12 to their parent PAHs and found that they did not differ significantly ( $t$ test, $p=0.05$ ) at two sites having similar distances from the source of emission.

The observed concentration ratios of $\mathrm{AQ}, \mathrm{PQ}$ and $\mathrm{B}(\mathrm{a}) \mathrm{A}$ 7,12 to parent-PAH during the sampling periods may be related to the air mass origin and used to assess the long range chemical transport and relative contribution of different sources to the concentrations of quinones. A paired $t$ test revealed the differences in quinone / PAH ratios (sum of vapour and particulate phase) of air masses from differing back trajectory regions to be statistically significant, for both winter $(p<0.05)$ and summer $(p<0.01)$ campaigns. During the winter, relatively low quinone / PAH ratios were observed when air masses originated from closer source regions such as London and Western Europe (17 February 2010 to 20 February 2010), see Fig. 2a. These ratios may therefore reflect the dominance of primary emissions upon the observed levels of quinones on these sampling days. In contrast, the levels of quinones relative to their parent PAH were notably enhanced for air masses originating from more remote areas away from regions with an abundance of primary emissions (see Fig. 2a, 11 February 2010 to 14 February 2010). This may therefore be indicative of an additional source contributing to levels of quinone, most probably oxidation reactions of PAHs occurring during long-range transport. Alternatively, it may reflect greater degradation of PAH than quinones during atmospheric transport, irrespective of the reaction products. Figure $2 \mathrm{a}$ illustrates that $53 \%$ of the quinone to parent-PAH ratios during the winter sampling period were in the order $\mathrm{B}(\mathrm{a}) \mathrm{A}-7,12 / \mathrm{B}(\mathrm{a}) \mathrm{A}>\mathrm{AQ} / \mathrm{ANT}>\mathrm{PQ} / \mathrm{PHE}$. This may be indicative of the atmospheric processing rates for these compounds. For example, PAHs can react with $\mathrm{OH}$ forming their respective quinone compounds where the second order reaction rate coefficient for the gas phase reaction of $\mathrm{PHE}+\mathrm{OH}$ is $3.2 \times 10^{-11} \mathrm{~cm}^{3}$ molecule $\mathrm{e}^{-1} \mathrm{~s}^{-1}$ (Lee et al., 2003) which is an order of magnitude slower than ANT + OH $\left(1.3 \times 10^{-10} \mathrm{~cm}^{3}\right.$ molecule $\left.\mathrm{s}^{-1} \mathrm{~s}^{-1}\right)$ (Atkinson and Arey, 1994). This corresponds to daytime lifetimes of $4.3 \mathrm{~h}$ and $1.1 \mathrm{~h}$ for PHE and ANT respectively, for $[\mathrm{OH}]=2 \times 10^{6}$ molecule $\mathrm{cm}^{-3}$; global $12 \mathrm{~h}$ average (Atkinson and Arey, 2007); and may account for the smaller ratios of PQ / PHE in comparison with AQ / ANT and B(a)A7,12/B(a)A. To date, however, no gas phase reaction rate coefficient has been measured for $\mathrm{B}(\mathrm{a}) \mathrm{A}$ with atmospheric oxidants, $\mathrm{OH}, \mathrm{O}_{3}$ or $\mathrm{NO}_{3}$, even though a significant proportion

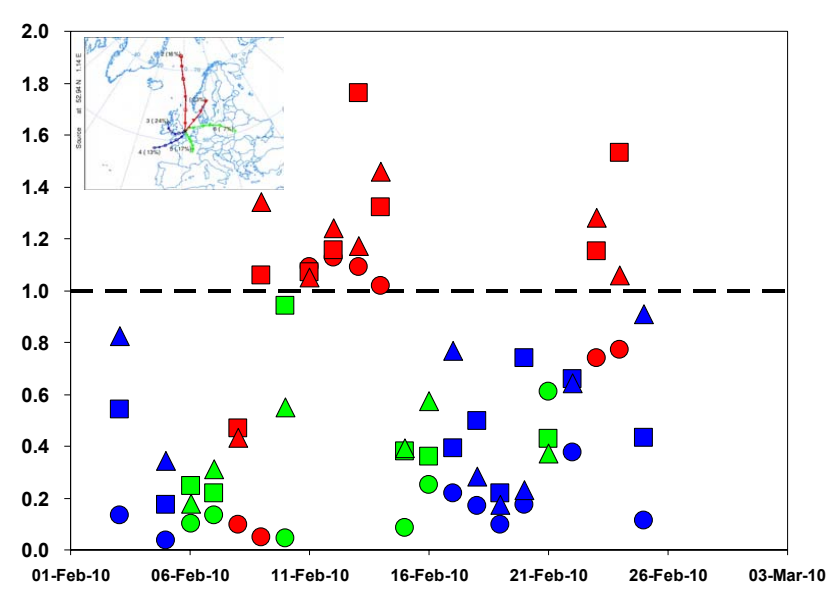

(A)

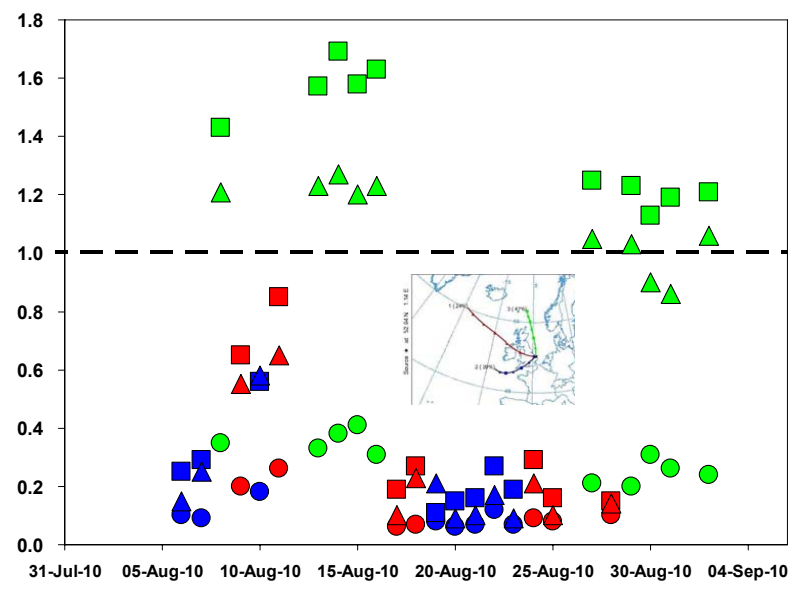

(B)

Fig. 2. Quinone to parent-PAH ratios (sum of vapour and particulate phases) during (A) winter and (B) summer. Circles - PQ / PHE; squares - AQ/ANT and triangles - B(a)A-7,12/B(a)A. Colours signify three different air masses determined by cluster analysis, see embedded image and/or Figs. S1a and S1b for colour codes.

of $\mathrm{B}(\mathrm{a}) \mathrm{A}$ is found to be present in the gas phase during winter (see Table 1). The ratios of $\mathrm{B}(\mathrm{a}) \mathrm{P}-6,12$ and $\mathrm{B}(\mathrm{a}) \mathrm{P}-1,6$ to $\mathrm{B}(\mathrm{a}) \mathrm{P}$ did not show a strong variation as demonstrated for $\mathrm{AQ}, \mathrm{PQ}$ and $\mathrm{B}(\mathrm{a}) \mathrm{A}-7,12$, with approximately $85 \%$ of the sampled ratios less than 0.5 . The observed ratios of particulate phase $\mathrm{AQ}, \mathrm{PQ}$ and $\mathrm{B}(\mathrm{a}) \mathrm{A}-7,12$ to parent-PAH during the winter sampling campaign (not shown) were found to be strongly related to their air mass origins, as shown in Fig. 2 for the sum of particulate and vapour. However, $77 \%$ of the particulate quinone to parent-PAH ratios were in the order AQ / ANT > B(a)A-7,12/B(a)A > PQ / PHE and the ratios were in the order of $0.1-2.9$, larger than the ratios determined for the sum of vapour and particulate compounds of 0.04-1.8 shown in Fig. 2a.

During the summer a more pronounced difference was observed between total quinone / PAH ratios of air masses originating from "polluted" and "non-polluted" regions, 
see Fig. 2b. Again, relatively larger quinone / PAH ratios were observed when air masses originated from remote areas away from regions with high primary emissions (see Fig. 2b, 13 August 2010 to 16 August 2010 and 29 August 2010 to 2 September 2010), particularly for ratios AQ / ANT and B(a)A-7,12/B(a)A. Unlike the winter data, however, $88 \%$ of the quinone to parent-PAH ratios were in the order AQ / ANT > B(a)A-7,12/B(a)A > PQ / PHE. To assess whether atmospheric processing rates were at all responsible for this observation during the summer, total $\mathrm{AQ} / \mathrm{ANT}: \mathrm{PQ} / \mathrm{PHE}$ ratios were calculated for the three cluster trajectories. The average total AQ / ANT : PQ / PHE ratios determined for green (remote, North Sea), blue (London and Western Europe) and red (mainland UK and Ireland) trajectories were 5.1, 2.5 and 2.2, respectively. The larger ratio calculated for remote areas, as well as the higher concentrations of AQ observed during the summer relative to the winter, suggests greater atmospheric processing rates for faster reacting PAHs during long range transport.

Approximately 77 and $56 \%$ of the particulate quinone to parent-PAH ratios during the winter and summer sampling period were also in the order $\mathrm{AQ} / \mathrm{ANT}>\mathrm{B}(\mathrm{a}) \mathrm{A}$ 7,12/B(a)A > PQ / PHE, respectively. This is consistent with relative rates of heterogeneous processing for these compounds. For example, Perraudin et al. $(2005,2007)$ investigated the kinetics of the reactions of atmospheric oxidants and PAHs adsorbed on model atmospheric particles. They found that whatever the conditions of the particle loading, the ozone concentration and nature of the particles, ANT and $\mathrm{B}(\mathrm{a}) \mathrm{A}$ were the most reactive towards ozone oxidation (Perraudin et al., 2007), where the absolute reaction rates for $\mathrm{ANT}+\mathrm{O}_{3}$ was an order to magnitude faster than $\mathrm{PHE}+\mathrm{O}_{3}$. Similarly, particulate PHE was found to be less reactive towards $\mathrm{NO}_{2}$ and not considered to be degraded at atmospherically relevant $\mathrm{NO}_{2}$ concentrations (Perraudin et al., 2005). ANT and B(a)A, however, were found to react up to 3 orders of magnitude faster, and when adsorbed on silica particles, their lifetime relative to $\mathrm{NO}_{2}$ oxidation may be shorter than a few hours in polluted conditions. Calculated lifetimes for ANT, $\mathrm{B}(\mathrm{a}) \mathrm{A}$ and PHE with respect to $\mathrm{NO}_{2}$ using the reaction rate coefficients determined by Perraudin et al. (2005) and a yearly average $\left[\mathrm{NO}_{2}\right]$ of $1.3 \times 10^{11}$ molecule $\mathrm{cm}^{-3}$, determined at Harwell, UK (2011) are $4 \mathrm{~h}, 60 \mathrm{~h}$ and $1460 \mathrm{~h}$, respectively. These kinetic observations may explain the ordering of the particulate ratios and the relatively low PQ to PHE particulate ratios determined during the summer sampling campaign. However, the variation in the literature for heterogeneous reaction rate coefficients of PAHs means that it is difficult to infer the rates of PAH conversion to their derivative compounds. Such a discussion also ignores the active re-partitioning of PAH and their oxidation products between particle and vapour phases and the role of vapour as a reactant and a component of the product mixture.

\subsection{PAH reactivity}

The differences in PAH congener profiles between rural and urban sites can indicate the extent of PAH reactivity within the atmosphere, where rural sites should show a much more aged profile than urban sites. However, relatively small differences in the PAH profiles from nearby urban and rural sites are typically seen (Mari et al., 2010; Sanderson et al., 2004), and it has been suggested that atmospheric transformations of PAHs may be of relatively little importance. A comparison of congener profiles for urban (data from Alam et al., 2013) (Birmingham, UK) and rural (this study - Weybourne, UK) sites is illustrated in Fig. 3. The concentrations of PAHs and quinones determined at Weybourne are a result of emissions that have undergone long range transport, whereas concentrations from the urban site (Elms Road Observatory Site, EROS), which are an order of magnitude larger, are representative of urban source area composition. Mari et al. (2010) reported the similarity of PAH congener profiles between urban and nearby rural sites, and showed no consistent pattern of change in the relative concentrations of PAHs. Concentrations at rural sites were lower than urban sites, which is a result of dilution processes in the urban plume, and is also demonstrated in the data presented in this study. In contrast to Mari et al. (2010), Figure 3 suggests a substantial difference within the ranking related to PYR, B(b)F, B(k)F, IND and B(ghi)P for PAHs and PQ for quinone compounds. This may arise because of different sources, rates of atmospheric processing, or of deposition. For example, the ratio of FLU / PYR for rural and urban sites was 2.06 and 0.78 , respectively (see Fig. 3); suggesting that PYR may be more reactive than FLU and is consistent with the gas phase absolute reaction rates determined with respect to $\mathrm{OH}$ of $2.20 \times 10^{-5} \mathrm{~s}^{-1}$ (Brubaker and Hites, 1998) and $1.00 \times 10^{-4} \mathrm{~s}^{-1}$ (Atkinson et al., 1990) for FLU and PYR, respectively. This is also consistent with the gas phase absolute rate constants determined with respect to $\mathrm{NO}_{3}$ (Atkinson et al., 1990) and heterogeneous absolute rates calculated with respect to $\mathrm{OH}$ (Bedjanian et al., 2010; Esteve et al., 2006), $\mathrm{NO}_{2}$ (Esteve et al., 2004, 2006; Perraudin et al., 2005) and $\mathrm{O}_{3}$ (Perraudin et al., 2007), suggesting that PYR may have a higher susceptibility to atmospheric processing than FLU. This is however in contrast with the isomeric ratio of FLU / PYR for the individual trajectories calculated during the winter which are 2.06, 2.15 and 1.01 for London and mainland UK (blue), eastern and southern Europe (green) and North Sea and Scandinavia (red), respectively, which may suggest different ratios in the different source areas.

A difference in the ranking relating to PQ was also observed between the two sites (see Fig. 3), where elevated levels of PQ were observed at EROS. This could indicate a direct emission source of this species from traffic (Alam et al., 2013). The average quinone to parent-PAH ratios for PQ / PHE, AQ / ANT and B(a)A-7,12 / B(a)A are shown in 

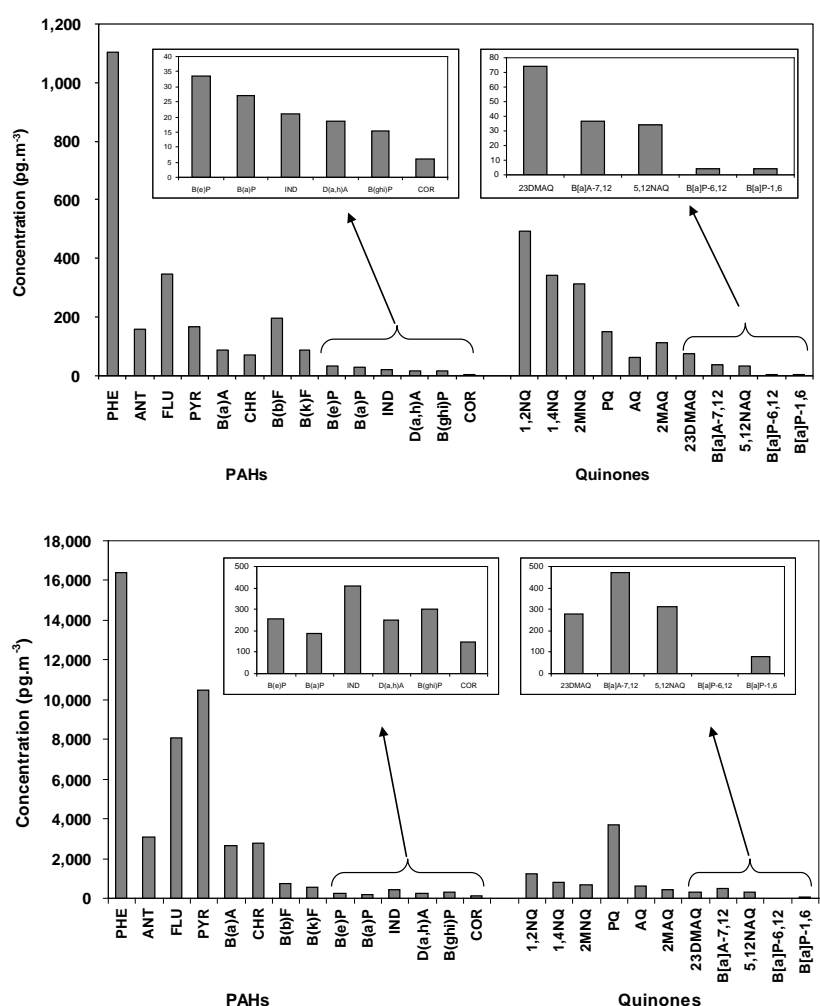

Fig. 3. Average PAH profile (sum of particulate and vapour phase) from (top graph) Weybourne and (lower graph) Elms Road Observatory site (Birmingham).

Table S2. The elevated ratios observed at Weybourne for AQ / ANT and B(a)A-7,12 / B(a)A may be attributed to the occurrence of oxidation reactions of PAHs occurring during long range transport. The more similar ratios obtained at the two sites for PQ/PHE suggests that the atmospheric processing rate of PHE may be slower than ANT and B(a)A, consistent with the ordering of quinone / parent-PAH ratios discussed for Fig. 2.

The ratios of urban / rural PAH and quinone concentrations are illustrated in Fig. 4. This ratio can be used to assess the reactivity of PAH and quinone compounds. Figure 4 shows a substantial difference in the ratios depending upon where the air masses are originating from. For example, the ratios calculated using rural data where air masses originate from relatively local source areas, such as London/mainland UK (Fig. 4, blue bars) and mainland Europe (Fig. 4, green bars) are very similar and relatively small, in comparison to the larger ratios calculated when the air masses originate from "remote" areas, such as the North Sea (Fig. 4, red bars). If it is assumed that the ratios of emitted PAH are similar, the larger ratios may be attributed to the occurrence of oxidation reactions of PAHs occurring during long range transport from these remote areas, whereas the smaller ratios determined from polluted areas will be modified less. Lohmann and Lammel (2004) point out that the annual mean concen-

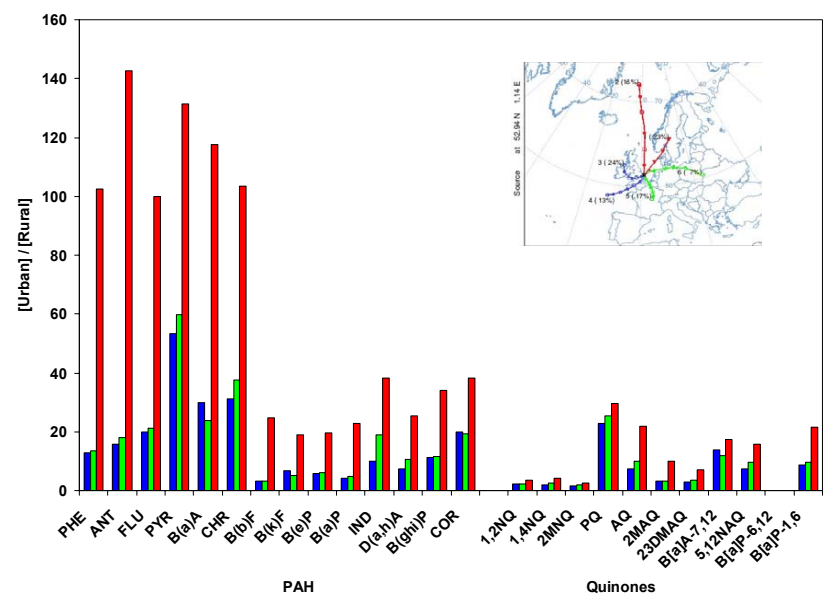

Fig. 4. Winter ratio of compound concentrations measured at EROS, Birmingham, UK to species concentrations measured at Weybourne, UK. Blue - ratios determined using average concentrations of air masses travelling from mainland UK and London; Green ratios determined using average concentrations calculated from air masses arriving from mainland Europe; Red - ratios determined using average concentrations calculated from air masses travelling from the North Sea

tration of $\mathrm{B}(\mathrm{a}) \mathrm{P}$ measured at a background site in central Europe is only slightly higher than that measured in the Canadian Arctic while for PHE the European site has a vastly higher concentration. They cite evidence that particle-bound PAH are not depleted during their transport. The largest calculated ratios are those of the LMW species, which is consistent with these species being subject to more rapid vapour phase loss due to greater reactivity. According to the standalone ratios calculated using remote air mass rural data (see Fig. 4), the reactivity of the LMW PAHs are in the following order: ANT $>$ PYR $>$ B (a)A $>$ CHR $>$ PHE $>$ FLU, which is consistent with the relative magnitudes of vapour phase reaction rate coefficients with respect to $\mathrm{OH}$ (Atkinson and Arey, 2007; Atkinson et al., 1990, 1989; Biermann et al., 1985; Brubaker and Hites, 1998; Kwok et al., 1994), as shown in Table 2. The lower ratio for most quinones in Fig. 4 relative to their parent PAH can be explained either by the production of these compounds by atmospheric reactions or their greater stability relative to $\mathrm{PAH}$, which has yet to be established adequately, but which is suggested by laboratory studies of their formation.

\section{Conclusions}

The choice of Weybourne as a site for measurements was based upon its exposure both to polluted air masses advected from southern England, continental European air masses and far cleaner air traversing the North Sea from the Arctic. In the event, air masses representative of all three sources were sampled, and show interesting differential behaviour, 
Table 2. Average gas phase rate coefficients of LMW PAH compounds found in literature and their corresponding calculated urban / rural reactivity ratios.

\begin{tabular}{lrrr}
\hline PAH & $\begin{array}{r}\text { Urban/ } \\
\text { Rural } \\
\text { Ratios }^{\mathrm{a}}\end{array}$ & $\begin{array}{r}\text { Second order rate } \\
\text { constant, } k\left(\mathrm{~cm}^{3}\right. \\
\left.\text { molecules }^{-1} \mathrm{~s}^{-1}\right)^{\mathrm{b}}\end{array}$ & $\begin{array}{r}\text { Absolute } \\
\text { rate }\left(\mathrm{s}^{-1}\right)^{\mathrm{c}}\end{array}$ \\
\hline ANT & 143 & $1.29 \times 10^{-10}$ & $2.59 \times 10^{-4}$ \\
PYR & 131 & $5.00 \times 10^{-11}$ & $1.00 \times 10^{-4}$ \\
$\left.\mathrm{~B}^{\mathrm{a}}\right)_{\mathrm{A}}{ }^{\mathrm{d}}$ & 118 & & \\
$\mathrm{CHR}^{\mathrm{d}}$ & 103 & & \\
PHE & 102 & $2.54 \times 10^{-11}$ & $5.09 \times 10^{-5}$ \\
FLU & 100 & $1.10 \times 10^{-11}$ & $2.20 \times 10^{-5}$ \\
\hline
\end{tabular}

${ }^{\mathrm{a}}$ Urban / rural ratios calculated using remote air mass rural data (see Fig. 4, red bars).

b Average second order rate coefficient calculated from NIST kinetics

database, http://kinetics.nist.gov/kinetics/index.jsp.

${ }^{c}$ Absolute rate with respect to $\mathrm{OH}$. $[\mathrm{OH}]=2 \times 10^{6}$ molecules $\mathrm{cm}^{-3}$.

${ }^{\mathrm{d}}$ No gas phase rate coefficient data reported in literature.

particularly during the summer. The fact that the losses of 3/4 ring PAH correlate with their vapour phase reactivity towards the hydroxyl radical confirms the results of laboratory studies suggesting this as the key reactant. The far smaller loss of high molecular weight compounds in comparison to the lower molecular weight species confirms the relative stability of the former and that the high reaction rates in heterogeneous processes seen in some laboratory studies are probably not occurring in the atmosphere.

The far greater relative losses of low molecular weight PAH than of quinones in the more aged air masses indicate either a greater atmospheric stability of the quinones, or their formation during atmospheric transport, or both processes. Some quinones, notably 1,4-naphthaquinone, and anthraquinone show evidence of atmospheric formation in their considerably greater relative abundance in the summer than the winter campaign.

\section{Supplementary material related to this article is available online at http://www.atmos-chem-phys.net/14/ 2467/2014/acp-14-2467-2014-supplement.pdf.}

Acknowledgements. The funding by the UK Natural Environment Research Council is gratefully acknowledged (grant reference number NE/F016581/1). Authors wish to thank A. Jones, E. Goosey, S. Cumberland, B. Roulle and R. Johnson for their collaboration during sampling. Authors thank B. Bandy for logistic support and site access. The underlying research materials for this study, i.e. data used, can be accessed via email requesting information to m.s.alam@bham.ac.uk.

Edited by: X. Querol

\section{References}

Alam, M. S., Delgado-Saborit, J. M., Stark, C., and Harrison, R. M.: Using atmospheric measurements of PAH and quinone compounds at roadside and urban background sites to assess sources and reactivity, Atmos. Environ., 77, 24-35, 2013.

Albinet, A., Leoz-Garziandia, E., Budzinski, H., and Villenave, E. Simultaneous analysis of oxygenated and nitrated polycyclic aromatic hydrocarbons on standard reference material 1649a (urban dust) and on natural ambient air samples by gas chromatographymass spectrometry with negative ion chemical ionisation, J. Chromatogr. A, 1121, 106-113, 2006.

Albinet, A., Leoz-Garziandia, E., Budzinski, H., and Villenave, E.: Polycyclic aromatic hydrocarbons (PAHs), nitrated PAHs and oxygenated PAHs in ambient air of the Marseilles area (South of France): Concentrations and sources, Sci. Total Environ., 384, 280-292, 2007a.

Albinet, A., Leoz-Garziandia, E., Budzinski, H., and Villenave, E.: Sampling precautions for the measurement of nitrated polycyclic aromatic hydrocarbons in ambient air, Atmos. Environ., 41, 4988-4994, 2007b.

Albinet, A., Leoz-Garziandia, E., Budzinski, H., Villenave, E., and Jaffrezo, J. L.: Nitrated and oxygenated derivatives of polycyclic aromatic hydrocarbons in the ambient air of two French alpine valleys - Part 1: Concentrations, sources and gas/particle partitioning, Atmos. Environ., 42, 43-54, 2008a.

Albinet, A., Leoz-Garziandia, E., Budzinski, H., Villenave, E., and Jaffrezo, J. L.: Nitrated and oxygenated derivatives of polycyclic aromatic hydrocarbons in the ambient air of two French alpine valleys - Part 2: Particle size distribution, Atmos. Environ., 42, 55-64, 2008b.

Atkinson, R. and Arey, J.: Atmospheric chemistry of gas-phase polycyclic aromatic-hydrocarbons - formation of atmospheric mutagens, Environ. Health Persp., 102, 117-126, 1994.

Atkinson, R. and Arey, J.: Mechanisms of the gas-phase reactions of aromatic hydrocarbons and $\mathrm{PAHs}$ with $\mathrm{OH}$ and $\mathrm{NO}_{3}$ radicals, Polycycl. Aromat. Comp., 27, 15-40, 2007.

Atkinson, R., Baulch, D. L., Cox, R. A., Hampson, R. F., Kerr, J. A., and Troe, J.: Evaluated kinetic and photochemical data for atmospheric chemistry. 3. Iupac subcommittee on gas kinetic data evaluation for atmospheric chemistry, J. Phys. Chem. Ref. Data, 18, 881-1097, 1989.

Atkinson, R., Arey, J., Zielinska, B., and Aschmann, S. M.: Kinetics and nitro-products of the gas-phase $\mathrm{OH}$ and $\mathrm{NO}_{3}$ radicalinitiated reactions of naphthalene-d8, fluoranthene-d10, and pyrene, Int. J. Chem. Kinet., 22, 999-1014, 1990.

Bari, Md. A., Baumbach, G., Kuch, B., and Scheffknecht, G.: Wood smoke as a source of particle-phase organic compounds in residential areas, Atmos. Environ., 43, 4722-4732, 2009.

Bedjanian, Y., Nguyen, M. L., and Le-Bras, G.: Kinetics of the reactions of soot surface-bound polycyclic aromatic hydrocarbons with the OH radicals, Atmos. Environ., 44, 1754-1760, 2010.

Biermann, H. W., Macleod, H., Atkinson, R., Winer, A. M., and Pitts, J. N.: Kinetics of the gas-phase reactions of the hydroxyl radical with naphthalene, phenanthrene, and anthracene, Environ. Sci. Technol., 19, 244-248, 1985.

Brubaker, W. W. and Hites, R. A.: $\mathrm{OH}$ reaction kinetics of polycyclic aromatic hydrocarbons and polychlorinated dibenzo-pdioxins and dibenzofurans, J. Phys. Chem. A, 102, 915-921, 1998. 
Cardenas, L. M., Austin, J. F., Burgess, R. A., Clemitshaw, K. C., Dorling, S., Penkett, S. A., and Harrison, R. M.: Correlations between $\mathrm{CO}, \mathrm{NO}_{\mathrm{y}}, \mathrm{O}_{3}$ and other non-methane hydrocarbons and their relationships with meteorology during winter 1993 on the north Norfolk coast, UK, Atmos. Environ., 32, 3339-3351, 1998.

Cho, A. K., Di Stefano, E., You, Y., Rodriguez, C. E., Schmitz, D. A., Kumagai, Y., Miguel, A. H., Eiguren-Fernandez, A., Kobayashi, T., Avol, E., and Froines, J. R.: Determination of four quinones in diesel exhaust particles, SRM 1649a, an atmospheric $\mathrm{PM}_{2.5}$, Aerosol Sci. Tech., 38, 68-81, 2004.

Chung, M. Y., Lazaro, R. A., Lim, D., Jackson, J., Lyon, J., Rendulic, D., and Hasson, A. S.: Aerosol-borne quinones and reactive oxygen species generation by particulate matter extracts, Environ. Sci. Technol., 40, 4880-4886, 2006.

Delgado-Saborit, J. M., Alam, M. S., Godri, K. J., Stark, C., and Harrison, R. M.: Analysis of atmospheric concentration of quinones and polycyclic aromatic hydrocarbons in vapour and particulate phases, Atmos. Environ., 77, 974-982, 2013a.

Delgado-Saborit, J. M., Stark, C., and Harrison, P. M.: Use of a versatile high efficiency multiparallel denuder for the sampling of PAHs in ambient air: gas and particle phase concentrations, particle size distribution and artifact formation, Environ. Sci. Technol., 48, 499-507, 2014.

Eiguren-Fernandez, A., Miguel, A. H., Froines, J. R., Thurairatnam, S., and Avol, E. L.: Seasonal and spatial variation of polycyclic aromatic hydrocarbons in vapor-phase and $\mathrm{PM}_{2.5}$ in Southern California urban and rural communities, Aerosol Sci. Tech., 38, 447-455, 2004.

Eiguren-Fernandez, A., Miguel, A. H., Di Stefano, E., Schmitz, D. A., Cho, A. K., Thurairatnam, S., Avol, E. L., and Froines, J. R.: Atmospheric distribution of gas- and particle-phase quinones in Southern California, Aerosol Sci. Tech., 42, 854-861, 2008.

Esteve, W., Budzinski, H., and Villenave, E.: Relative rate constants for the heterogeneous reactions of $\mathrm{OH}, \mathrm{NO}_{2}$ and $\mathrm{NO}$ radicals with polycyclic aromatic hydrocarbons adsorbed on carbonaceous particles. Part 1: PAHs adsorbed on 1-2 mu m calibrated graphite particles, Atmos. Environ., 38, 6063-6072, 2004.

Esteve, W., Budzinski, H., and Villenave, E.: Relative rate constants for the heterogeneous reactions of $\mathrm{NO}_{2}$ and $\mathrm{OH}$ radicals with polycyclic aromatic hydrocarbons adsorbed on carbonaceous particles. Part 2: PAHs adsorbed on diesel particulate exhaust SRM 1650a, Atmos. Environ., 40, 201-211, 2006.

Harrison, R. M., Smith, D. J. T., and Luhana, L.: Source apportionment of atmospheric polycyclic aromatic hydrocarbons collected from an urban location in Birmingham, UK, Environ. Sci. Technol., 30, 825-832, 1996.

Iinuma, Y., Brueggemann, E., Gnauk, T., Mueller, K., Andreae, M. O., Helas, G., Parmar, R., and Herrmann, H.: Source characterization of biomass burning particles: The combustion of selected European conifers, African hardwood, savanna grass, and German and Indonesian peat, J. Geophys. Res.-Atmos., 112, D08209, doi:10.1029/2006JD007120, 2007.

Jakober, C. A., Riddle, S. G., Robert, M. A., Destaillats, H., Charles, M. J., Green, P. G., and Kleeman, M. J.: Quinone emissions from gasoline and diesel motor vehicles, Environ. Sci. Technol., 41, 4548-4554, 2007.

Keyte, I. J., Harrison, R. M., and Lammel, G.: Chemical Reactivity and long-range transport potential of polycyclic aromatic hydrocarbons - A review, Chem. Soc. Rev., 42, 9333-9391, 2013.
Kwok, E. S. C., Harger, W. P., Arey, J., and Atkinson, R.: Reactions of gas-phase phenanthrene under simulated atmospheric conditions, Environ. Sci. Technol., 28, 521-527, 1994.

Layshock, J. A., Wilson, G., and Anderson, K. A.: Ketone and quinone-substituted polycyclic aromatic hydrocarbons in mussel tissue, sediment, urban dust, and diesel particulate matrices, Environ. Toxicol. Chem., 29, 2450-2460, 2010.

Lee, W., Stevens, P. S., and Hites, R. A.: Rate constants for the gasphase reactions of methylphenanthrenes with $\mathrm{OH}$ as a function of temperature, J. Phys. Chem. A, 107, 6603-6608, 2003.

Lohmann, R. and Lammel, G.: Adsorptive and absorptive contributions to the gas-particle partitioning of polycyclic aromatic hydrocarbons: State of knowledge and recommended parameterization for modeling, Environ. Sci. Technol., 38, 3793-3803, 2004.

Mari, M., Harrison, R. M., Schuhmacher, M., Domingo, J. L., and Pongpiachan, S.: Inferences over the sources and processes affecting polycyclic aromatic hydrocarbons in the atmosphere derived from measured data, Sci. Total Environ., 408, 2387-2393, 2010.

McKinney, R. A., Pruell, R. J., and Burgess, R. M.: Ratio of the concentration of anthraquinone to anthracene in coastal marine sediments, Chemosphere, 38, 2415-2430, 1999.

Miguel, A. H., Eiguren-Fernandez, A., Jaques, P. A., Froines, J. R., Grant, B. L., Mayo, P. R., and Sioutas, C.: Seasonal variation of the particle size distribution of polycyclic aromatic hydrocarbons and of major aerosol species in Claremont, California, Atmos. Environ., 38, 3241-3251, 2004.

Penkett, S. A., Plane, J. M. C., Comes, F. J., Clemitshaw, K. C., and Coe, H.: The Weybourne Atmospheric Observatory, J. Atmos. Chem., 33, 107-110, 1999.

Perraudin, E., Budzinski, H., and Villenave, E.: Kinetic study of the reactions of $\mathrm{NO}_{2}$ with polycyclic aromatic hydrocarbons adsorbed on silica particles, Atmos. Environ., 39, 6557-6567, 2005.

Perraudin, E., Budzinski, H., and Villenave, E.: Kinetic study of the reactions of ozone with polycyclic aromatic hydrocarbons adsorbed on atmospheric model particles, J. Atmos. Chem., 56, 57-82, 2007.

Sanderson, E. G., Raqbi, A., Vyskocil, A., and Farant, J. P.: Comparison of particulate polycyclic aromatic hydrocarbon profiles in different regions of Canada, Atmos. Environ., 38, 3417-3429, 2004.

Sidhu, S., Gullett, B., Striebich, R., Klosterman, J., Contreras, J., and DeVito, M. L.: Endocrine disrupting chemical emissions from combustion sources: diesel particulate emissions and domestic waste open burn emissions, Atmos.Environ., 39, 801-811, 2005.

Valavanidis, A., Fiotakis, K., Vlahogianni, T., Papadimitriou, V., and Pantikaki, V.: Determination of selective quinones and quinoid radicals in airborne particulate matter and vehicular exhaust particles, Environ. Chem., 3, 118-123, 2006.

Vestenius, M., Leppanen, S., Anttila, P., Kyllonen, K., Hatakka, J., Hellen, H., Hyvarinen, A.-P., and Hakola, H.: Background concentrations and source apportionment of polycyclic aromatic hydrocarbons in south-eastern Finland, Atmos. Environ., 45, 33913399, 2011.

Walgraeve, C., Demeestere, K., Dewulf, J., Zimmermann, R., and Van Langenhove, H.: Oxygenated polycyclic aromatic hydrocarbons in atmospheric particulate matter: Molecular 
characterization and occurrence, Atmos. Environ., 44, 18311846, 2010.

Wang, W., Jariyasopit, N., Schrlau, J., Jia, Y., Tao, S., Yu, T.-W., Dashwood, R. H., Zhang, W., Wang, X., and Simonich, S. L. M.: Concentration and Photochemistry of PAHs, NPAHs, and OPAHs and Toxicity of $\mathrm{PM}(2.5)$ during the Beijing Olympic Games, Environ. Sci. Technol., 45, 6887-6895, 2011.
Wingfors, H., Hagglund, L., and Magnusson, R.: Characterization of the size-distribution of aerosols and particle-bound content of oxygenated PAHs, PAHs, and n-alkanes in urban environments in Afghanistan, Atmos. Environ., 45, 4360-4369, 2011.

Yu, H.: Environmental carcinogenic polycyclic aromatic hydrocarbons: photochemistry and phototoxicity, J. Environ. Sci. Heal. C, 20, 149-183, 2002. 